\title{
CINÉTICA DA ADSORÇÃO DE OURO CONTIDO EM SOLUÇÕES LIXIVIADAS DE MICROPROCESSADORES UTILIZANDO QUITINA COMO ADSORVENTE
}

\author{
L. N. CORTES ${ }^{1}$, J. M. N. dos $\operatorname{SANTOS}^{1}$, G. L. DOTTO ${ }^{1}$ \\ ${ }^{1}$ Universidade Federal de Santa Maria, Departamento de Engenharia Química \\ E-mail para contato: leticiancortes@hotmail.com; guilherme_dotto@yahoo.com.br \\ RESUMO - Neste trabalho, ouro foi extraído de microprocessadores e após, \\ recuperado da solução extratora por adsorção utilizando quitina. Curvas cinéticas \\ de adsorção foram obtidas utilizando as soluções lixiviadas antes e após uma \\ precipitação adicional. $\mathrm{O}$ modelo de pseudo-segunda ordem foi o mais adequado \\ para representar os dados da cinética de adsorção de ouro. As capacidades de \\ adsorção foram de 37,9 e $35,2 \mathrm{mg} \mathrm{g}^{-1}$ para as soluções antes e após a precipitação.
}

\section{INTRODUÇÃO}

Em 1971, a Intel lançou o primeiro microprocessador comercial e, segundo dados da Associação Brasileira da Indústria Elétrica e Eletrônica (Abinee), só no primeiro semestre de 2013 foram vendidos no país 10,4 milhões de unidades de computadores. No geral, quem compra um eletrônico acaba se desfazendo de outro. Portanto, o Brasil acabou se tornando um dos campeões mundiais na geração de lixo eletrônico de informática. No entanto, estes resíduos eletrônicos, como por exemplo, os microprocessadores, possuem metais de valor em sua composição, os quais podem ser recuperados. Segundo Ubaldini et al. (1997) o uso da tioureia como agente de extração de metais preciosos é de alto valor para a indústria metalúrgica. A lixiviação com tioureia passou a ser uma considerável alternativa para a lixiviação de ouro, como forma de reaproveitamento de materiais eletrônicos descartados.

Após a extração com tioureia, o ouro e demais metais contidos nos microprocessadores ficam em solução aquosa, necessitando-se de operações para sua recuperação e posterior concentração. Segundo Repo et al. (2011), a adsorção é um dos métodos mais eficazes para a recuperação de metais pesados a partir de meios aquosos. $\mathrm{O}$ adsorvente mais comum aplicado é o carvão ativado, porém é de alto custo, o que o torna economicamente inviável em processos industriais. O estudo de adsorventes alternativos tem crescido nos últimos tempos. Materiais de baixo custo são de grande interesse, como a quitina, que é derivada de resíduos da indústria pesqueira (DOTTO et al., 2013). Assim este trabalho possui um forte viés ambiental, utilizando operações unitárias como adsorção e extração, para recuperar ouro a partir de resíduos eletrônicos, tendo como o adsorvente, um material também derivado de resíduos, a quitina.

Este estudo teve como objetivo realizar a extração de ouro de microprocessadores e, estudar a adsorção de ouro das soluções extratoras antes e após uma precipitação adicional. Os modelos cinéticos de pseudo-primeira ordem e pseudo-segunda ordem foram utilizados para representar as curvas experimentais da adsorção de oura em quitina. 


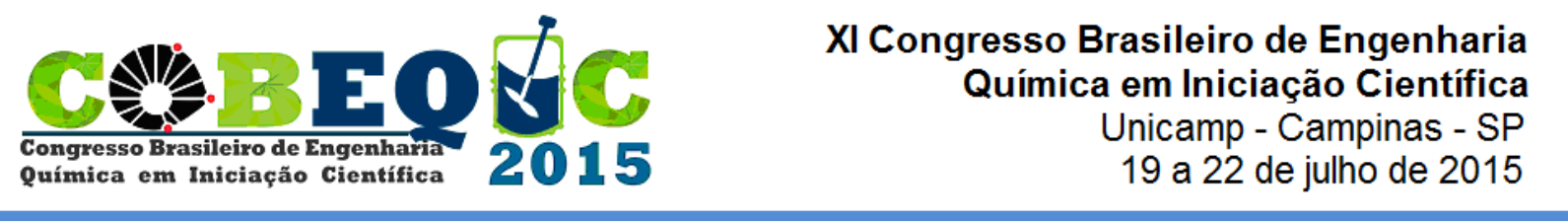

\section{METODOLOGIA}

\subsection{Obtenção da quitina}

A quitina foi obtida a partir de cascas de camarão (P. brasiliensis). Os resíduos foram submetidos à desmineralização, desproteinização, desodorização e secagem (DOTTO et al., 2013). A quitina obtida foi moída (Wiley padrão, modelo 03) e peneirada, até que fosse obtido o tamanho de partícula variando entre 105-125 $\mu \mathrm{m}$. O grau de desacetilação da quitina obtida foi $45 \pm 1 \%$.

\subsection{Caracterização dos microprocessadores e extração}

Os microprocessadores foram obtidos em ponto de coleta na cidade de Santa Maria RS. Os pinos foram retirados manualmente, caracterizados por MEV e EDS (JEOL, JSM 5800) e o ouro extraído destes, como se segue. Primeiramente foi quantificado o ouro nos pinos via extração com água régia. Após procedeu-se a extração com tioureia: em um balão, foram adicionados $1 \mathrm{~g}$ dos pinos, tioureia, ácido sulfúrico (até que o $\mathrm{pH}$ atingisse valores de 1.00) e aproximadamente, $0.3 \mathrm{~g}$ de sulfato férrico (UBALDINI et al., 1997). Variou-se o tempo entre 10, 20, 30, 60 e 120 minutos, a temperatura ambiente. As soluções lixiviadas, contendo ouro complexado e demais metais extraídos, foram armazenadas no escuro para posteriores ensaios de adsorção. Todas as amostras foram filtradas e os metais analisados por espectrometria de absorção atômica

\subsection{Ensaios de Adsorção}

Foram realizados dois ensaios cinéticos de adsorção em um banho termostático agitado (DIST DI 950M). No primeiro, adicionou-se, aproximadamente 0,02 g de quitina em Erlenmeyers contendo $20 \mathrm{~mL}$ de solução lixiviada $(\mathrm{pH}<<<1,00)$, sob agitação constante de $150 \mathrm{rpm}$. Amostras foram coletadas entre 0 e 120 minutos. A segunda foi realizada utilizando as mesmas condições de da primeira, porém antes da adsorção, precipitou-se o ferro presente em solução para tentar potencializar o efeito da quitina. Para a precipitação do ferro, foi utilizada solução de $\mathrm{NaOH} 5 \mathrm{~mol} \mathrm{~L}^{-1}$, até que a solução atingisse pH 6 . A capacidade de adsorção foi obtida pela Equação 1:

$$
q_{t}=\frac{V\left(C_{0}-C_{t}\right)}{m}
$$

onde, $C_{0}$ é a concentração inicial de ouro ou ferro em solução $\left(\mathrm{mg} \mathrm{L}^{-1}\right), C_{t}$ é a concentração de ouro ou ferro, em solução, no intervalo de tempo considerado $\left(\mathrm{mg} \mathrm{L}^{-1}\right), m$ é a massa de adsorvente (g) e $V$ é o volume de solução (L).

\subsection{Modelos Cinéticos}

A fim de estudar o comportamento cinético de adsorção, as curvas experimentais foram ajustadas aos modelos de pseudo-primeira ordem e pseudo-segunda ordem, representados pelas Equações 2 e 3 , respectivamente: 


$$
\begin{aligned}
& q_{t}=q_{1}\left(1-\exp \left(-k_{1} t\right)\right) \\
& q_{t}=\frac{t}{\left(1 / k_{2} q_{2}^{2}\right)+\left(t / q_{2}\right)}
\end{aligned}
$$

onde, $\mathrm{k}_{1}\left(\mathrm{~min}^{-1}\right)$ e $\mathrm{k}_{2}\left(\mathrm{mg} \mathrm{g}^{-1} \min ^{-1}\right)$ são as constantes da taxa dos modelos; $\mathrm{q}_{1}$ e $\mathrm{q}_{2}\left(\mathrm{mg} \mathrm{g}^{-1}\right)$, os valores teóricos para a capacidade de adsorção.

Os parâmetros cinéticos foram determinados a partir do ajuste dos dados experimentais aos modelos, através de regressão não linear. Os cálculos foram feitos utilizando o software Statistic 9.1 (Statsoft). A qualidade do ajuste foi verificada através do coeficiente de determinação $\left(\mathrm{R}^{2}\right)$ e erro médio relativo (ARE).

\section{RESULTADOS E DISCUSSÃO}

\subsection{Caracterização da matéria prima}

O microprocessador possui pinos revestidos de ouro. A Figura 1a apresenta a imagem de MEV dos processadores utilizados. A Figura $1 \mathrm{~b}$ apresenta o espectro de EDS com a respectiva composição química. Como pode-se observar, o maior pico é do ouro, contendo uma composição de $87,4 \%$. Outros elementos como ferro $(0,8 \%)$ e alumínio $(1,7 \%)$ também estão presentes, porém em porcentagens relativamente pequenas (a presença destes metais esta associada à composição química da liga, que forma o metal da parte interna dos pinos).

Figura 1-MEV e EDS dos pinos de microprocessadores

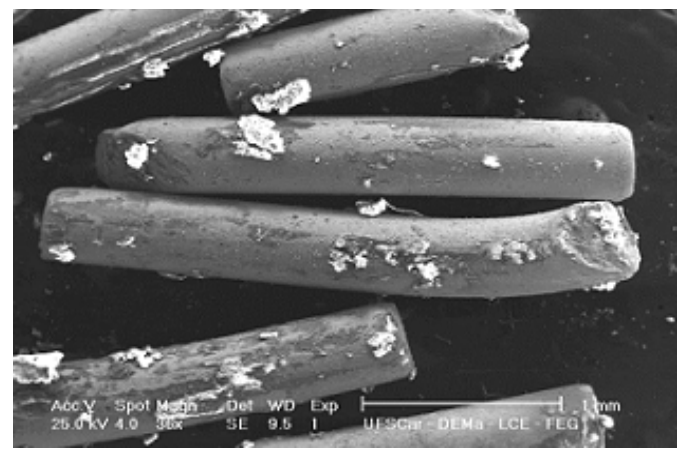

(a)

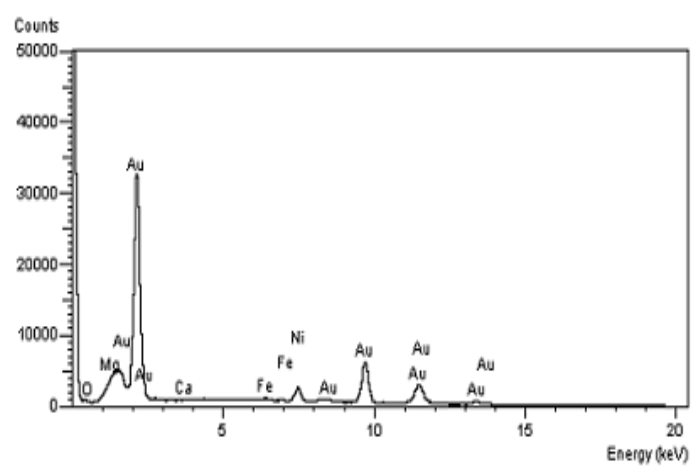

(b)

A Figura 2 apresenta a concentração de ouro, presente em solução lixiviada de água régia, em função do tempo de extração. Esta figura foi utilizada para fixar o percentual de ouro total contido nos pinos. A partir da Figura 2, observou-se que com 3h de extração foi possível obter a maior concentração de massa de ouro. Assim, verificou-se, quer cada g de pino fornece uma concentração de $57 \mathrm{mg} \mathrm{L}^{-1}$ de ouro em um volume experimental fixo. Este valor foi considerado como sendo $100 \%$ de ouro para as extrações posteriores. 
Figura 2 - Gráfico da concentração de ouro $\left(\mathrm{mg} \mathrm{L}^{-1}\right)$ em solução de água régia, em função do tempo de extração

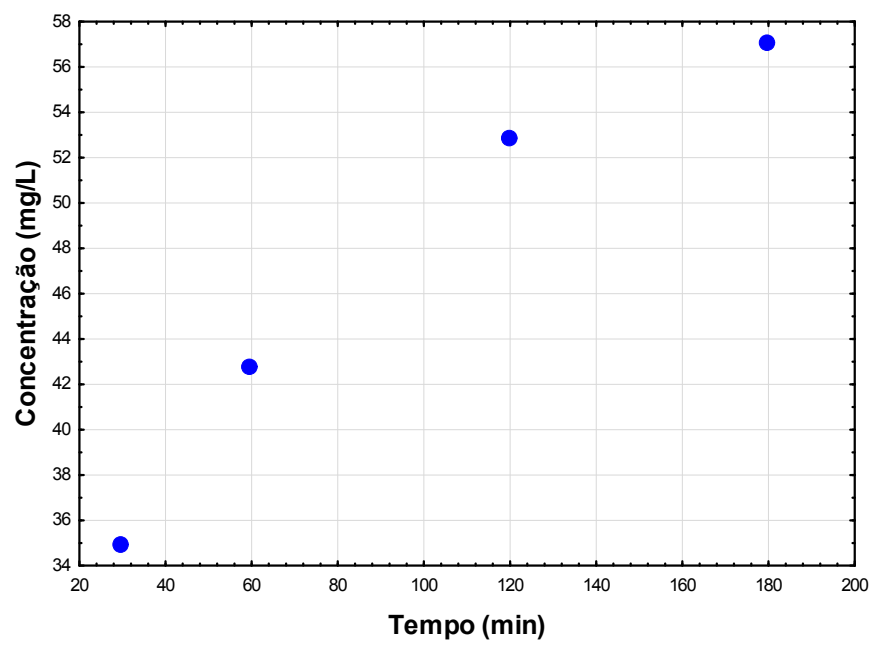

\subsection{Extração ácida de ouro dos microprocessadores}

A Figura 3 apresenta o percentual de extração do ouro utilizando tioureia ácida como agente lixiviante.

Figura 3 - Percentual de extração de ouro na lixiviação

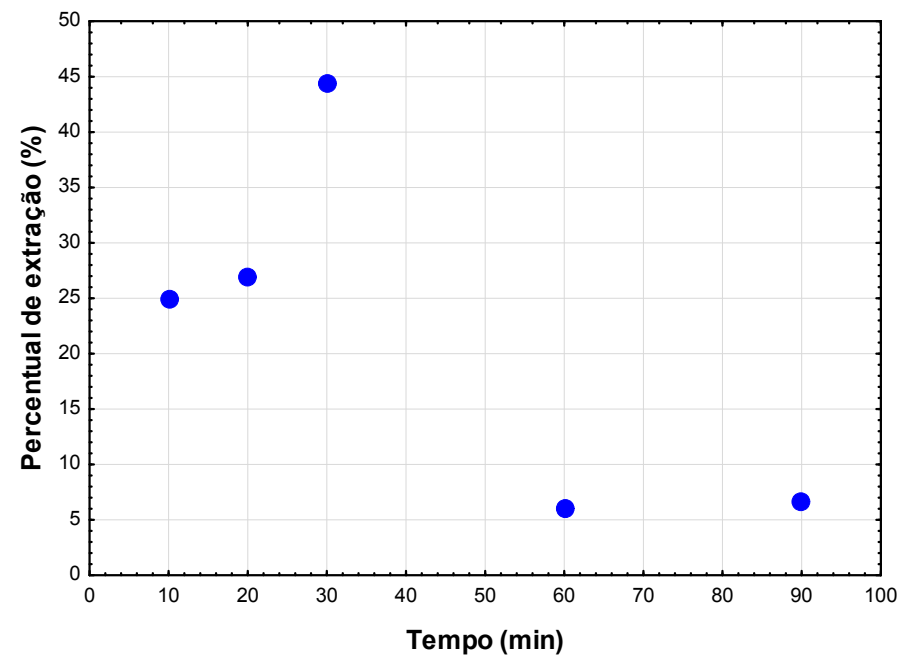

Verificou-se na Figura 3, que o percentual de extração aumentou com o aumento do tempo de reação, alcançando o máximo percentual de 45,5\% após 30 min. Após, o percentual de extração começa a diminuir. Este comportamento ainda está sendo estudado, porém YING et al., (2012) verificou comportamento similar.

\subsection{Adsorção de ouro das soluções lixiviadas}

A adsorção com quitina foi realizada antes e após a precipitação do ferro. A solução antes da precipitação continha $2816,5 \mathrm{mg} \mathrm{L}^{-1}$ de ferro e $202,8 \mathrm{mg} \mathrm{L}^{-1}$ de ouro com $\mathrm{pH}<<<1,00$. A solução após a precipitação continha com $4,0 \mathrm{mg} \mathrm{L}^{-1}$ de ferro e $98,5 \mathrm{mg} \mathrm{L}^{-1} \mathrm{de}$ 
ouro com $\mathrm{pH}=6,00$. No entanto, a solução após a precipitação tinha o dobro do volume. Verificou-se que a precipitação foi eficiente, retirando praticamente todo o ferro da solução e mantendo o ouro. As curvas cinéticas da adsorção de ouro e ferro em quitina antes da precipitação estão mostradas na Figura 4.

Figura 4- Cinética de ouro e ferro antes da precipitação
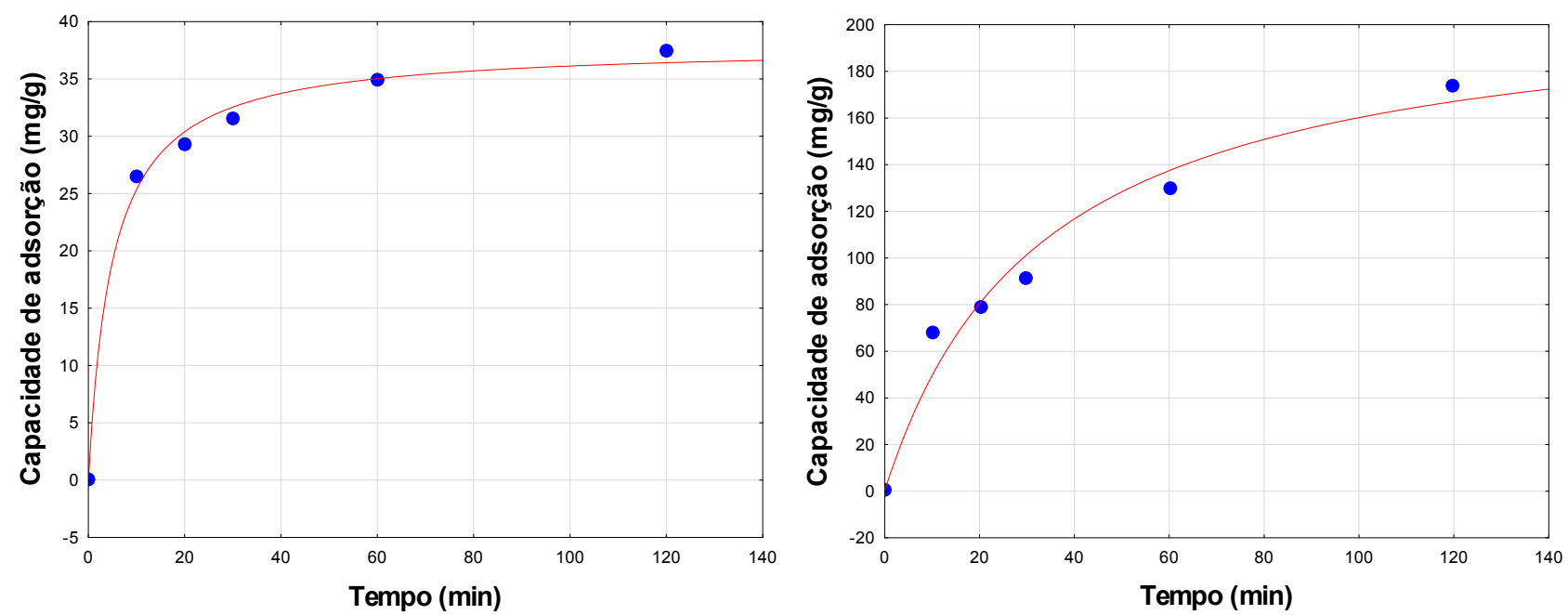

Nas figuras acima, é possível analisar que a capacidade de adsorção aumenta com o aumento do tempo reacional, chegando por volta de $37,5 \mathrm{mg} \mathrm{g}^{-1}$ para o ouro e $174,5 \mathrm{mg} \mathrm{g}^{-1}$ para o ferro. A curva cinética da adsorção de ouro após a precipitação está apresentada na Figura 5.

Figura 5 - Cinética de ouro depois da precipitação do ferro

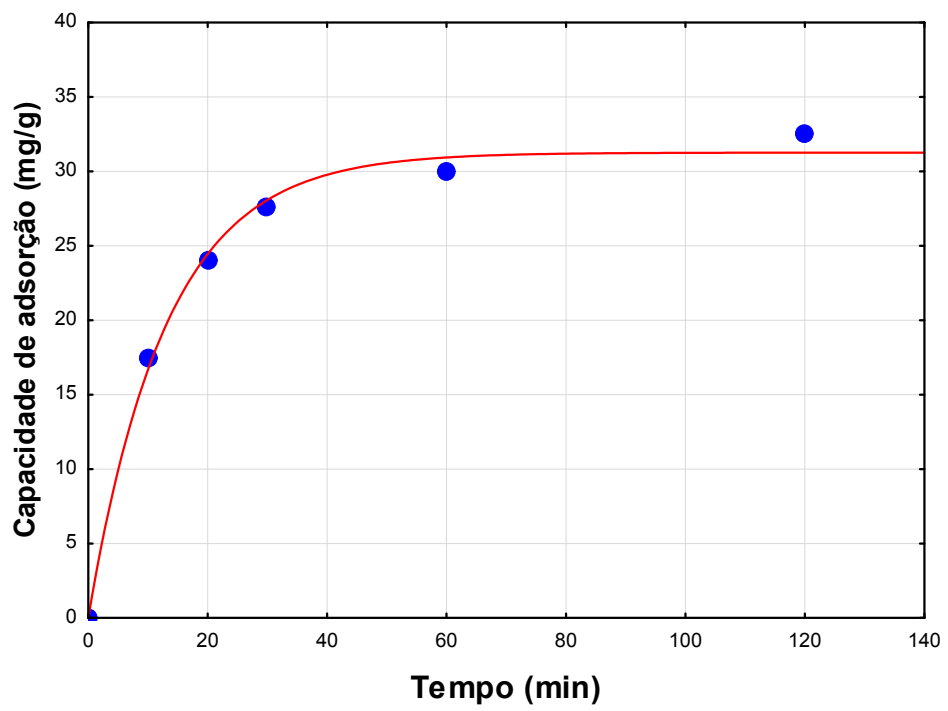

Na Figura 5 pode-se observar que a capacidade de adsorção aumenta com o aumento do tempo, ainda que depois da precipitação o volume em solução tenha praticamente dobrado, a capacidade de adsorção se mostrou na mesma faixa. Na Tabela 1, estão apresentados os parâmetros obtidos a partir do ajuste de dados aos modelos cinéticos. 
Tabela 1 - Parâmetros Cinéticos para Adsorção de Ouro em Quitina

\begin{tabular}{ccc}
\hline & \multicolumn{2}{c}{ Curva Cinética } \\
\cline { 2 - 3 } Modelos & Au (antes da precipitação) & $\begin{array}{c}\text { Au (depois da } \\
\text { precipitação) }\end{array}$ \\
\hline Pseudo-primeira Ordem & & 32,3 \\
\hline $\mathrm{q}_{1}\left(\mathrm{mg} \mathrm{g}^{-1}\right)$ & 34,7 & 0,076 \\
$\mathrm{k}_{1}\left(\mathrm{~min}^{-1}\right)$ & 0,123 & 0,9951 \\
$\mathrm{R}^{2}$ & 0,9742 & 2,54 \\
$\mathrm{ARE}(\%)$ & 5,34 & 35,2 \\
\hline Pseudo-segunda Ordem & & 0,00297 \\
$\mathrm{q}_{2}\left(\mathrm{mg} \mathrm{g}^{-1}\right)$ & 37,9 & 0,9982 \\
$\mathrm{k}_{2}\left(\mathrm{mg} \mathrm{g}^{-1} \mathrm{~min}^{-1}\right.$ & 0,00532 & 1,44 \\
$\mathrm{R}^{2}$ & 0,9944 & \\
$\mathrm{ARE}(\%)$ & 2,51 & \\
\hline
\end{tabular}

Verificou-se que o modelo de pseudo-segunda ordem foi o mais adequado para representar os dados cinéticos de adsorção de ouro em quitina. A precipitação dobrou o volume da solução lixiviada, e consequentemente reduziu pela metade a concentração de ouro, porém a capacidade de adsorção de ouro em quitina reduziu apenas $7 \%$. Isso mostra que a precipitação do ferro teve um efeito benéfico para a posterior recuperação do ouro pela quitina.

\section{CONCLUSÕES}

A lixiviação com tioureia é um processo limpo, que não causa impacto ambiental, tornando-se uma alternativa para a reutilização de materiais, podendo recuperar uma quantidade apreciável de ouro (44,5\%) presente nos microprocessadores em apenas um estágio de extração. Considerando a adsorção de solução lixiviada de ouro em quitina, o modelo de pseudo-segunda ordem foi o mais adequado para representar os dados de cinética. As capacidades de adsorção foram de 37,9 e $35,2 \mathrm{mg} \mathrm{g}^{-1}$ para as soluções antes e após a precipitação. Verificou-se que a precipitação do ferro deve ser realizada antes da adsorção a fim de obter apenas o ouro na fase sólida para posterior processamento.

\section{REFERENCIAS}

DOTTO, G.L.; ROSA, G.S.; MORAES, M.A.; WESKA, R.F.; PINTO, L.A.A. Treatment of chitin effluents by coagulation-flocculation with chitin and aluminum sulfate. J. Environ. Chem. Eng. 1, p. 50-55, 2013.

REPO, E.; WARCHOL, J. K.; BHATNAGAR, A.; SILLANPAA, M. Heavy metals adsorption by novel EDTA-modified chitosan silica hybrid materials. J. Of Colloid and Interface Science., v. 358, p. 261-267, 2011.

UBALDINI, S.; FORNARI, R. M.; ABBRUZZESE, C. An innovative thiourea gold leaching process. Hydrometallurgy., v.48, p. 113-124, 1998.

YING, J.L.; LI, X. X.; QUAN, W. L. Thiourea leaching gold and silver from the printed circuit boards of waste mobile phones. Waste Management. v.32, p.1209-1212, 2012. 